\title{
Soluciones del Derecho Internacional Privado para Deducir \\ Responsabilidad Civil por Daño Ambiental Transfronterizo en Honduras
}

\author{
Claudia María Castro Valle ${ }^{1}$ \\ Universidad Tecnológica Centroamericana (UNITEC), San Pedro Sula, Honduras
}

(Enviado: Agosto, 2014)

\begin{abstract}
Resumen:
Este documento se enfoca en la resolución de conflictos generados por la causación de daño al ambiente, y la responsabilidad patrimonial que este genera, particularmente cuando la contaminación trasciende las fronteras de un Estado y manifiesta sus efectos en otro.

Ante la complejidad de ese supuesto, se intenta ofrecer una explicación coherente de la forma en que esos conflictos podrían resolverse en el ámbito hondureño, considerando que la situación geográfica del país hace que sea muy probable la ocurrencia de una eventualidad de estas características, y determinar cuáles son las soluciones que el Derecho Internacional privado proporciona según el esquema normativo hondureño para resolver los supuestos transfronterizos en los que debe deducir la responsabilidad civil, tales como la competencia judicial internacional y la ley aplicable.
\end{abstract}

Palabras Claves: Ambiente, Daño Ambiental, Responsabilidad civil, Derecho Internacional privado.

\begin{abstract}
:
This paper focuses on the resolution of conflicts generated by the infliction of damage to the environment and the liability that it generates, particularly when its effects transcend state borders and affect a neighboring one.

Given the complexity of this subject, this is an attempt to provide a coherent explanation of how these conflicts could be resolved in the Honduran context, considering that the country's geographical location makes the occurrence of an event of this nature very likely. The paper intends to determine which solutions are provided by Private International Law according to the Honduran legal system for cross-border liability litigation.
\end{abstract}

Keywords: Environment, Environmental Damage, Liability, Private International Law.

\section{Introducción}

Quiero empezar reflexionando sobre el hombre y su empeño en construir ficciones, tales como las fronteras; a pesar de esto, es necesario reconocer que hay realidades que trascienden dichas ficciones y que no pueden ser controladas adecuadamente por el hombre mismo. El daño ambiental es un ejemplo claro de esa realidad, en tanto el desarrollo tecnológico e industrial ha alcanzado dimensiones tales, que cada vez es más real la amenaza de los efectos nocivos para la naturaleza que tenga su aplicación, y peor aún, que más de un Estado se vea afectado por estos (Martín Mateo, 1998, págs. 2-3).

De hecho, en la época más reciente, el número de accidentes ambientales con efectos transnacionales ha ido en aumento. Cómo olvidar ejemplos tan significativos como la

\footnotetext{
${ }^{1}$ Autor para correspondencia. Email: claudia.castro@unitec.edu
} 
fundición de plomo y zinc en Trail, Columbia Británica, cuyas emanaciones contaminaron tierras cultivables en EEUU; el accidente de «Seveso» en las cercanías de Milán, Italia; la fuga de petróleo del buque «Amoco-Cadiz» en la costa francesa; la contaminación del Rhin como consecuencia de un incendio en la fábrica de químicos «Sandoz» en Basilea; la explosión de un reactor de la central térmica en Chernóbil; el derrame de petróleo del buque «Exxon Valdez» en altamar; el derrame de petróleo del «Prestige» frente a las costas españolas; la explosión e incendio de la plataforma petrolífera en el golfo de México en 2010; y más recientemente, el accidente nuclear en Fukushima tras el terremoto que devastó el oriente del Japón, en marzo de 2011.

Como se puede fácilmente deducir, todos estos accidentes se originan en actividades industriales. Ahora que Centroamérica se ha incorporado al proceso de industrialización, la situación geográfica de Honduras la hace proclive a la posibilidad de un evento de similar naturaleza, en tanto cuenta con fronteras terrestres con tres Estados (Guatemala, El Salvador y Nicaragua) y tiene costas tanto en el océano Pacífico como en el mar Caribe. Por lo tanto, el propósito de este trabajo es establecer la idoneidad de los mecanismos disponibles en la legislación hondureña para la deducción de la responsabilidad civil por daños transfronterizos al ambiente, atendiendo las exigencias que plantea el Derecho ambiental para la tutela estos intereses, sean estos individuales, colectivos o difusos.

Para esto es necesario abordar los tres elementos que entran en juego. Inicialmente explicaré cómo la definición de «daño ambiental» puede suponer un problema, por no coincidir necesariamente con las características que tradicionalmente el Derecho civil ha establecido para configurar el concepto de «daño» (Egea Fernández, 2006, pág. 397). He incluido en ese apartado el caso de las inmisiones como una posibilidad adicional que merece ser tomada en cuenta ${ }^{2}$. Continúo abordando el instituto de la responsabilidad civil, ya que es necesario comprender las particularidades de la el tipo aquiliano específicamente (Cabanillas Sánchez, 2001, pág. 1149).

Todo lo anterior sirve como especie de preámbulo para poder comprender cómo el Derecho internacional, particularmente el privado $^{3}$, ha abordado esta temática, y cuáles son las soluciones de las que dispone en el contexto hondureño, haciendo énfasis en los problemas tradicionales que esta rama jurídica intenta resolver: la competencia judicial internacional (Esplugues Mota \& Iglesias Buhigues, 2011, pág. 92) y la ley aplicable (González Campos, 1991, págs. 292-293).

\footnotetext{
${ }^{2}$ Las inmisiones se encuentran reguladas en el artículo 2241.2 del Código civil, definiéndolas como «...humos excesivos, que sean nocivos a las personas o a las propiedades...».

${ }^{3}$ Esplugues Mota señala que el Derecho Internacional privado es parte del Derecho privado de un Estado, y que su objeto es regular las relaciones privadas de carácter internacional que son generadas entre particulares. Tiene como finalidad resolver los conflictos que devienen de la existencia de varios ordenamientos jurídicos que se vinculan a partir de una relación o situación jurídica concreta como posibles regímenes de regulación para estas, por existir en ellas al menos algún «elemento de extranjería». La existencia de dicho elemento de extranjería es precisamente lo que le da su carácter de internacionalidad, y supondrá el contacto de esa relación o situación jurídica con un ordenamiento distinto al del juez u operador que conoce el caso (Esplugues Mota \& Iglesias Buhigues, 2011, págs. 69-75).
} 


\section{El daño ambiental en la legislación hondureña}

Comenzaré por señalar que el legislador hondureño ha optado por incluir una definición muy amplia del ambiente en el ordenamiento jurídico vigente ${ }^{4}$. El artículo 2 de la Ley General del Ambiente (LGA) ${ }^{5}$ lo define como «...el conjunto formado por los recursos naturales, culturales y el espacio rural y urbano, que puede verse alterado por agentes físicos, químicos o biológicos, o por otros factores debido a causas naturales o actividades humanas, todos ellos susceptibles a afectar, directa o indirectamente, las condiciones de vida del hombre y el desarrollo de la sociedad».

Como se lee, este concepto incluye no solo elementos naturales, sino que culturales, y señala como derechos subjetivos a ser tutelados, «las condiciones de vida del hombre»y el «desarrollo de la sociedad». El legislador también señala que el ambiente puede ser objeto de alteraciones causadas por el hombre o causadas por la naturaleza.

El origen de las alteraciones al ambiente se puede ubicar en lo que la doctrina denomina actividades peligrosas o actividades riesgosas (Boqueiro Rojas, 1997, pág. 63). La diferencia entre ambas, radica en que las actividades peligrosas tienen un origen natural, mientras que las actividades riesgosas se originan en la actividad humana y están vinculadas con el desarrollo tecnológico (Esteve Pardo, 2006, págs. 8-9). De hecho las actividades riesgosas han servido normalmente para superar los peligros, y son precisamente estas, las de riesgo, las que interesan al Derecho ambiental.

Toca analizar si las alteraciones que el legislador ha señalado en el artículo 2 de la Ley General del Ambiente, pueden considerarse como daño desde el Derecho civil, el cual, según Roca Trías y Navarro Michel (Derecho de Daños, 2011), se define como «la lesión o menoscabo de un interés jurídicamente relevante» (195).

En este punto vale la pena señalar que la única definición de «daño ambiental» que nos ofrece la legislación hondureña se encuentra en el artículo 4 del Reglamento del Sistema Nacional de Evaluación de Impacto Ambiental (RSINEIA) ${ }^{6}$, como el «...impacto ambiental negativo no previsto ni controlado, ni planificado en un proceso de evaluación ambiental (evaluado ex-ante), producido directa o indirectamente por un proyecto, obra, industria u otra actividad, sobre todos o cualquiera de los componentes del ambiente que implican una alteración valorada como mínimo de alta significancia de impacto ambiental». Como es de esperarse, el RSINEIA nos ofrece una definición absolutamente técnica, ventajosa en el sentido de que logra objetivar las características del daño ambiental, sin embargo inútil desde la perspectiva del Derecho civil.

En esa definición queda claro que solo las actividades del hombre pueden considerarse como fuente de daño, y la doctrina agrega la idea que se considerará daño cuando las

\footnotetext{
${ }^{4}$ Es necesario señalar que la doctrina, al intentar ofrecer un concepto del ambiente, utiliza nociones que van desde la más restringida, que se limita a identificarlo con los recursos naturales, a otras intermedias que lo definen como un sistema equilibrado de componentes naturales que permite el desarrollo de la vida, hasta uno más amplio que incluye bienes naturales y culturales que permite que al contenido de este concepto se vayan agregando otros elementos (De La Barra Gili, 2002, pág. 374).

${ }^{5}$ Decreto No. 104-1993 del 8 de junio, publicado en el Diario Oficial La Gaceta \#27,083 el 30 de junio de 1993.

${ }^{6}$ Acuerdo No. 189-2009 del 7 de septiembre, publicado en el Diario Oficial La Gaceta \#32,102 el 31 de diciembre de 2009.
} 
actividades humanas no permitan que la naturaleza pueda autoregenerarse (Sebsay \& Di Paola, 2003, págs. 2-3). Cualquier alteración al ambiente o sus elementos, que sea de origen natural, no podría considerarse daño. A pesar de esto, estamos frente a una forma de daño tan amplia, que puede abarcar intereses privados o individuales, intereses colectivos e intereses difusos (Jordano Fraga, 2000, pág. 351).

De hecho, en Honduras, con la inclusión de las pretensiones las colectivas el Código Procesal civil ${ }^{7}$, el legislador reconoce el daño ambiental como un perjuicio a un derecho subjetivo público, que puede afectar intereses difusos y colectivos, además de derechos e intereses jurídicos individuales, como lo ha requerido tradicionalmente el Derecho civil (Jordano Fraga, 2000, pág. 351). Y es así porque el daño puede ser sufrido por el medio natural, como por las personas y sus bienes, tal como lo señala el artículo 53 de la Ley General del Ambiente, cuando al referirse a las razones que motivan la evaluación de impacto ambiental de instalaciones industriales, señala que hay vertidos o emisiones que pueden causar molestias o daños a «los habitantes o a sus bienes, a los suelos, agua, aire, flora y fauna silvestre».

Con relación a las características del daño ambiental, este puede ser difuso tanto porque se produce continuamente por diferentes agentes, a lo largo de un período extenso, dificultando su identificación e individualización (Álvarez Lata, 2002, pág. 794), como por la indeterminación del causante (Peña Chacón, 2006, pág. 34); y porque se proyecta en una colectividad indeterminable (Llamas Pombo, 2009, pág. 5). Esto presenta problemas con relación al deslinde de responsabilidades y en algunos casos, con la legitimización activa (Peña Chacón, 2006, pág. 34) ${ }^{8}$.

También es importante señalar que las leyes ambientales contienen regulaciones sobre estándares mínimos de tolerabilidad frente a la contaminación, considerándose que el daño aparece justo cuando estos límites son rebasados (Cabanillas Sánchez, 2001, pág. 1155). Como ejemplo de lo anterior en la legislación nacional, señala el artículo 77 del Reglamento de la Ley General del Ambiente (RLGA) ${ }^{9}$ que «...el Poder Ejecutivo, por medio de las Secretarías de Ambiente y Salud, establecerá los niveles permisibles de contaminación, atendiendo los resultados de las investigaciones que sean pertinentes y las normas internacionales».

La tolerabilidad viene a ser un requisito adicional pata el daño ambiental que no era previsto por la norma civil, y que se agrega a los de certeza (Corral Talciani, 1996, págs. 165-167) y significancia (De La Barra Gili, 2002, pág. 372). Además; sus efectos pueden

\footnotetext{
${ }^{7}$ Decreto No. 211-2006 del 20 de febrero de 2007, publicado en el Diario Oficial La Gaceta \#31,313 del 26 de mayo de 2007.

${ }^{8}$ La Corte Suprema de Justicia ha establecido en su sentencia SJCSJ-RI066 del 19 de octubre de 2006, refiriéndose a los derechos ambientales que «...en defensa de estos derechos, cualquier persona, sin distinción alguna, se encuentra legitimada y por ende comprometida para comparecer ante los órganos jurisdiccionales competentes. En virtud de todo lo expuesto es necesario entonces el reconocimiento de un jus standi apropiado para que toda persona natural en forma individual u organizada tenga acceso a la tutela judicial en defensa de los derechos que conciernen a la colectividad hondureña, derecho que se expresa en términos de legitimación como un interés difuso que no es abstracto sino real y concreto».

${ }^{9}$ Acuerdo No. 109-1993 del 20 de diciembre, Reglamento de la Ley General del Ambiente, publicado en el diario oficial La Gaceta \#27,267 del 5 de febrero de 1994.
} 
manifestarse más allá de la simple vecindad, e incluso trascender fronteras nacionales (Fernández De Gatta Sánchez, 2004, pág. 34).

Por otra parte, en la legislación hondureña hace falta un modelo único para la valoración económica del daño en términos generales y sobre todo cuando este es ambiental. También existen diferentes visiones con relación a la reparación entre ambas materias, porque lo que busca el Derecho ambiental no es el restablecimiento patrimonial del titular de los bienes deteriorados, sino el restablecimiento de las relaciones de interdependencia entre los diferentes elementos que conforman un ecosistema, reparando así los intereses de la colectividad (Egea Fernández, 2006, pág. 395).

También difiere en que el Derecho ambiental aboga porque la obligación de reparar sea siempre solidaria, sin embargo para la legislación civil hondureña, la solidaridad debe ser establecida expresamente por virtud de convenio, testamento o la ley, tal como lo señala el artículo 1400 del Código Civil ${ }^{10}$ (Martínez Vásquez De Castro, 1998, pág. 6).

El numeral f del artículo 87 de la Ley General del Ambiente establece que «cualquier acción u omisión de la normativa ambiental que constituya delito o infracción administrativa, dará lugar a la aplicación de las sanciones siguientes:... f) Indemnización al Estado o a terceros por los daños y perjuicios ocasionados al ambiente y a los recursos naturales...», se identifica una particularidad que es relevante señalar: el legislador ha optado por introducir en las últimas leyes ambientales la idea de que la reparación es una suerte de sanción como elemento de un sistema general de prevención, al estilo de los punitive damages del derecho anglosajón ${ }^{11}$, idea que choca de frente con el desarrollo doctrinal de la reparación según el derecho civil de nuestro sistema jurídico (Álvarez Lata, 2002, págs. 823-825) ${ }^{12}$.

En lo que a las inmisiones se refiere, como limitaciones al derecho a la propiedad sobre bienes inmuebles, pueden ofrecer una salida adicional para la deducción de la responsabilidad civil. El principio sic utere tuo ut alienum non laedas ${ }^{13}$, se puede vincular con el principio constitucional de la función social de la propiedad regulada, en al artículo 103 de la Carta Magna ${ }^{14}$. Pero más importante es el hecho de que su aplicación en defensa

\footnotetext{
${ }^{10}$ Decreto No. 76-1906 del 13 de enero, publicado el 19 de enero de 1906.

${ }^{11}$ La lógica detrás de los punitive damages o daños punitivos del Derecho anglosajón radica en evitar que una conducta dañosa se repita constantemente y con afán lucrativo, aún y cuando el causante haya indemnizado los perjuicios causados. A través de ellos se busca lograr la disuasión por medio de una sanción pecuniaria, la realización de una conducta o la entrega de una cosa. A diferencia de la indemnización por daños y perjuicios, el monto de estos no depende directamente de los daños acaecidos a los bienes, la economía o las personas de los individuos, sino que la extensión queda al arbitrio judicial, es decir, es imprevisible, quien atenderá a factores individuales del caso concreto para determinarlos (lucro obtenido causando enriquecimiento ilegítimo, dolo, repugnancia de la conducta, etc.), siendo normalmente mucho más elevados que el valor de la indemnización. Esto es así, porque lo que se busca es efectivamente modificar comportamientos inaceptables (Molina Sandoval, 2005, págs. 194-198).

${ }^{12}$ Sin embargo, es válido reconocer que hay autores que sí reconocen la conexión entre los punitive damages y el Civil Law, acercándolo a figuras como la multa civil, y justifican incluso su aplicación, como es el caso de Sidoli (2004).

${ }^{13}$ Voz latina que se traduce como, «...si usas la tuya, no dañes la propiedad ajena...»

${ }^{14}$ El artículo 103 de la Constitución de la República (Decreto No. 131-1982 del 1 de enero, publicado en el Diario Oficial La Gaceta \#23,612 el 20 de enero de 1982) establece que «el Estado reconoce, fomenta y garantiza la existencia de la propiedad privada en su más amplio concepto de función social y sin más limitaciones que aquellas que por motivos de necesidad o de interés público establezca la ley».
} 
del derecho subjetivo a la propiedad puede ser utilizada para la solución de problemas ambientales (Molina Sandoval, 2005, pág. 193).

\section{La responsabilidad civil para los supuestos de daño ambiental según el derecho civil hondureño}

La forma de solucionar por la vía civil los conflictos jurídicos que devienen del daño, supone la existencia de desafíos muy particulares, pues la naturaleza de los intereses jurídicos que intenta proteger el Derecho ambiental, difiere en alguna medida de los tutelados por el Derecho civil. Es así que este último se ocupa exclusivamente de intereses individuales, en tanto el ambiental busca tutelar también, intereses difusos y colectivos (Corral Talciani, 1996, pág. 168). Esto hace que haya quienes consideren que la vía civilista sea relativamente un fracaso para la solución del daño ambiental.

Es necesario entender la aplicabilidad en el contexto hondureño de la responsabilidad extracontractual o aquiliana para los supuestos de daño ambiental. Esta se basa en la existencia de la culpa o negligencia contenida en los artículos 2236 al 2243 del Código Civil. Lo más importante de este análisis radica en determinar si este sistema se adscribe a la Teoría del Riesgo o Responsabilidad Objetiva, o la Teoría de la Culpa o Responsabilidad Subjetiva.

En el caso de Honduras, el modelo del Código civil se adscribe en su mayoría a la Teoría de la Culpa o responsabilidad subjetiva, pues descansa en la culpabilidad de las conductas. Aunque en lo que a la negligencia se refiere, el legislador ha objetivado la responsabilidad, pasando la culpabilidad a ser un criterio secundario, y algunas veces, inexistente. Esto es así porque el legislador ha caracterizado las diferentes manifestaciones de la negligencia como «responsabilidades presuntas», como las denomina Tamayo Jaramillo (De la responsabilidad civil, 1986, pág. 5).

\section{Las soluciones del derecho internacional privado}

El último elemento a analizar se vincula a la dimensión transfronteriza que ciertos daños al ambiente han alcanzado en la historia reciente, obligando a la internacionalización de la regulación usada para resolver estos conflictos jurídicos (Bourel, 1994, pág. 95). Esta internacionalización se alcanzará por dos vías: el Derecho Internacional público y el Derecho Internacional privado.

El principio sic utere tuo ut alienum non laedas, que da pie a la regulación de las inmisiones, también ha servido para darle pie a los tratados internacionales que se han suscrito con relación a esta temática (García Castrejón, 2006, pág. 470). El Derecho Internacional público ha abordado la responsabilidad civil de los Estados por daño ambiental. El ejemplo más representativo es el Convenio del Consejo de Europa sobre la responsabilidad civil por los daños derivados de actividades peligrosas para el medio ambiente, conocido como Convenio de Lugano de 1993.

Sin embargo la realidad es que los Estados se muestran reacios a admitir su responsabilidad en este sentido, favoreciendo que esta se traslade directamente al contaminador que genera el daño (Gomis Catalá, 1998, págs. 32-33). De ahí que se haya creado instrumentos internacionales que contienen normas conflictuales que permiten 
solucionar casos concretos de responsabilidad civil internacional por daño ambiental transfronterizo. Particularmente es relevante para el caso hondureño la Convención Internacional sobre Responsabilidad Civil por daños debidos a la contaminación por hidrocarburos, de Bruselas, en 1969, porque es el único instrumento que contiene estas normas conflictuales, que ha sido ratificado por el Estado de Honduras.

Es obvia la diferencia entre las realidades jurídicas hondureña y europea, donde no solo está vigente el tratado antes mencionado, sino otros sobre hidrocarburos y daño nuclear, que según Siqueiros (2002, pág. 193), son las dos materias en las que existen instrumentos en las que se han uniformado normas conflictuales relativas a la responsabilidad civil internacional. Además se ha emitido en Europa la Directiva 2004/35/CE del 21 de abril, sobre responsabilidad medioambiental en relación con la prevención y reparación de daños ambientales, con su posterior trasposición a las legislaciones nacionales de los estados miembro, al igual que el Reglamento Roma II y el Reglamento Bruselas I.

Dado que son evidentemente limitadas las opciones disponibles desde el Derecho Internacional público para el caso hondureño, es obligatorio referirse entonces al sistema del Derecho Internacional privado vigente.

Lo primero que corresponde analizar es si los tribunales hondureños son competentes internacionalmente para conocer acciones para deducir responsabilidad civil por daño al ambiente transfronterizo. Por una parte, el ámbito territorial de las normas procesales civiles hondureñas y la extensión y límites del orden jurisdicción civil es establecido por el Código Procesal Civil, regulación que presenta verdaderas patologías en tanto remite a cuerpos normativos que nunca han existido en el ordenamiento jurídico hondureño, como se demuestra a continuación.

El ámbito territorial de las normas procesales es establecido en el artículo 21.2 del Código Procesal Civil ${ }^{15}$ cuando señala que «los procesos que se sustancien en territorio nacional, se rigen por este Código, las normas constitucionales y por los tratados y convenios internacionales». Esta normativa también se refiere a la extensión y límites del orden jurisdicción civil, señalando en su artículo 24.1 que «la jurisdicción en el ámbito civil solo podrá ser ejercida por los órganos del Poder Judicial. La extensión y límites de la jurisdicción de los tribunales civiles, se determinará por lo dispuesto en la Ley Orgánica del Poder Judicial, y en los tratados y convenios internacionales en los que Honduras sea parte».

Sin embargo no existe en el Derecho vigente hondureño ninguna Ley Orgánica del Poder Judicial. En Honduras sigue rigiendo el Decreto 76, Ley de Organización y Atribución de Tribunales que data de $1906^{16}$. La única referencia que esta ley hace en este sentido se encuentra en su artículo 5, el que establece que «los Juzgados y Tribunales solo podrán ejercer su jurisdicción en los asuntos y dentro del territorio que les hubieren designado las leyes, lo cual no impide que en los asuntos de que conocen puedan dictar providencias que hayan de llevarse a efecto en otro territorio».

\footnotetext{
${ }^{15}$ Decreto No. 211-2006 del 20 de febrero de 2007, publicado en el Diario Oficial La Gaceta \#31,313 el 26 de mayo de 2007.

${ }^{16}$ Decreto No. 76-1906 del 13 de enero, publicado el 19 de enero de 1906.
} 
Por otra parte, Honduras, al haber ratificado la Convención de Bruselas de 1969, ha reconocido la competencia judicial internacional de carácter exclusivo aplicando el principio forum iniurae o foro del lugar donde se produce el daño, como manifestación del forum delicti comissi o foro del lugar de la comisión del ilícito, sin que se permita que el demandado aplique la autonomía de la voluntad. Sin embargo; es necesario en este punto señalar que Honduras no ha suscrito los protocolos del 84 y del 92 que modifican a esta convención, lo que hace cuestionable su verdadera aplicabilidad.

Para todos aquellos otros supuestos que no queden ahí cubiertos, será aplicable lo dispuesto en el Código de Bustamante, ratificado por Honduras en 1930. Como regla general, este Código opta por la autonomía de la voluntad a través de la sumisión expresa o tácita de las partes, salvo que el derecho local establezca lo contrario (Art. 318). Subsidiariamente, prescribe la competencia del juez del lugar del cumplimiento de la obligación, y en su defecto el del domicilio de los demandados, y secundariamente el de su residencia (Art. 323).

La falta de desarrollo normativo por parte del legislador en este ámbito ha impedido que se prueben fórmulas que parecen haber sido efectivas en otras latitudes, tales como la otra manifestación del forum delicti comissi, es decir, el forum locus acti o foro del lugar donde se realiza la acción contaminante (Palao Moreno, 1998, pág. 58). Esta opción es particularmente efectiva si se considera que normalmente coincide el lugar de la acción con el domicilio del causante, lo que facilita la posterior ejecución de la sentencia.

Tampoco se ha considerado la aplicación del principio de ubicuidad u optio fori, cuya ventaja residiría en la opción que tiene el demandante para escoger el foro que más le convenga (Palao Moreno, 1998, pág. 58). Ni la del forum rei sitae, la que tradicionalmente ha implicado que el propietario del bien objeto del daño solo puede demandar ante tribunal ubicado en el lugar donde se sitúa dicho bien (Betlem, 1993, págs. 141-144).

Habiendo establecido los casos en que son competentes de conocer los tribunales hondureños, es necesario ahora determinar qué normativa sería la que corresponde aplicar para resolver el fondo de estos conflictos.

El Código Civil, que contiene las normas conflictuales en Honduras, no hace ninguna referencia con relación al régimen específico que debe aplicarse para las obligaciones extracontractuales, ni tampoco normas específicas para los supuestos de daño ambiental transfronterizo, por lo que es necesario referirse a instrumentos de Derecho Internacional público que han sido suscritos y ratificados por este Estado en materia de Derecho Internacional privado.

Reaparece aquí el Código de Bustamante. Este establece que las obligaciones extracontractuales se regirán por el derecho del lugar en que se hubiere incurrido en la negligencia o la culpa que las origine (Art. 168). Ese principio es el que la doctrina denomina lex loci delicti commissi, ubicando el lugar de comisión del ilícito en el lugar donde se lleva a cabo el acto que origina el daño (Siqueiros, 2002, pág. 190). Utilizar este principio supone una conexión de fácil aplicación, pero también presenta desventajas, como la rigidez que deviene de su naturaleza puramente territorial, particularmente en los supuestos donde la contaminación se realice fuera de la soberanía de cualquier Estado, o 
en aquellos donde el lugar de la acción contaminante no coincida con el de sus efectos (Palao Moreno, 1998, pág. 355).

Comparándolo con las soluciones existentes en el ámbito europeo, vale destacar que el Código Bustamante se aleja en este aspecto con el Reglamento Roma II, el que reconoce la elección de las partes como regla general para definir la ley aplicable. La lex loci actus delicti o la ley del lugar donde se lleva a cabo el ilícito, también es aplicable según este reglamento, pero de manera subsidiaria.

El legislador hondureño ha desestimado por lo tanto utilizar otras soluciones reconocidas en el Derecho Internacional privado, como es la locus damni o lugar donde se sufre el daño, que ofrece como ventajas su adecuación a las características propias del daño ambiental; también permite que se pueda deducir la responsabilidad al causante del daño sin que exista la posibilidad de exoneración, que supondría que este cumpla con las normas administrativas de tolerabilidad del Estado de origen (Palao Moreno, 1998, págs. 110-113). Tampoco ha pensado en la teoría de la ubicuidad, que ha recibido reseñas favorables por parte de la doctrina cuando se aplica en supuestos de daño ambiental transfronterizo (Kadner Graziano, 2007, págs. 74-75).

Al no haber más tratados internacionales a los que referirse, una solución de carácter general que sí nos ofrece el Código Civil hondureño es la del principio lex rei sitae o ley del lugar donde se ubican los bienes. Señala el artículo 14 del Código Civil que «los bienes situados en Honduras están sujetos a las leyes hondureñas aunque sus dueños sean extranjeros y no residan en Honduras. Esta disposición se entenderá sin perjuicio de las estipulaciones contenidas en los contratos celebrados válidamente en país extranjero».

Aunque normalmente se entiende que la aplicación de este principio se refiere más bien a casos en que se debata sobre el ejercicio de derechos reales sobre bienes inmuebles, podría flexibilizarse la interpretación y utilizarse en los casos de menoscabos a esta suerte de cosas, como sucede con las inmisiones, y como ha sido aplicado en Alemania, en el caso específico de los perjuicios causados por la construcción del Aeropuerto de Zúrich (Fach Gómez, 2004, pág. 295).

\section{Conclusiones}

Ojalá el análisis que se ha desarrollado, sirva al menos de disparador de una discusión jurídica que permita que la legislación hondureña se renueve y actualice, abriéndose a las soluciones más vanguardistas que la doctrina propone para abordar conflictos ambientales, que si bien aún o no ha acontecido en el ámbito nacional, no son imposibles porque Honduras también está inmersa en los procesos productivos y comerciales que son propios de la globalización.

La Constitución de la República, al recoger el derecho a la salud, al acceso al agua y saneamiento en su artículo 145, otorga significancia jurídica al ambiente, convirtiéndolo en un interés que amerita ser tutelado por el Estado. Esa significancia jurídica se consolida con la promulgación de la legislación ambiental nacional, la cual contiene una visión amplísima sobre el ambiente, lo que hace que dentro de la tutela del ambiente, como un todo indivisible, se reconozca que está conformado por bienes de dominio público y de dominio privado, los que deberán ser protegidos por la vía del Derecho privado. Sin 
embargo las características de los institutos propios del Derecho civil, no coinciden necesariamente con las necesidades que el Derecho ambiental requiere para la adecuada tutela de los bienes y servicios ambientales. Esto es particularmente evidente en la configuración del concepto de daño y de responsabilidad civil.

Los problemas de aplicación de la responsabilidad civil para deducir daño ambiental se manifiestan en varios ámbitos que van desde la falta de un sistema de valoración de bienes y servicios ambientales, el requerimiento de que la solidaridad sea expresa, el predominio de la responsabilidad subjetiva o Teoría de la Culpa, hasta la posibilidad de indemnizar como equivalente a la reparación in situ. A esto habría que agregar la incorporación en nuestra legislación ambiental de conceptos ajenos a nuestra tradición civilista, tales como el reconocimiento de la reparación como forma de sanción en las normas administrativas ambientales.

La indivisibilidad del ambiente obliga a entender que las soluciones para el problema ambiental tampoco pueden limitarse a un sólo ordenamiento jurídico, forzando la cooperación interestatal, la que se concretará por medio del Derecho Internacional público y el Derecho Internacional privado. El primero atiende a la responsabilidad civil de los Estados, quien debe actuar como contralor de las conductas dañosas de los particulares a él vinculados. Ante la poca anuencia de los Estados mismos de asumir esta responsabilidad se justifica la aplicación del segundo, ofreciendo mecanismos que permitan trasladar esa responsabilidad a los particulares mismos.

En lo que a Honduras se refiere, solo se ha ratificado un instrumento internacional que contiene normas conflictuales que podrían ser aplicables para supuestos de responsabilidad civil por daño ambiental: la Convención Internacional sobre Responsabilidad Civil por Daños debidos a la Contaminación por Hidrocarburos. De ahí que, para los supuestos que no estén previstos en esa Convención, deberá aplicarse las soluciones comunes del sistema propio de Derecho Internacional privado, que se reducen al Código Civil y al Código de Bustamante, ambos instrumentos desfasados y anquilosados.

\section{Bibliografía}

Álvarez Lata, N. (2002). El daño ambiental. Presente y futuro de su reparación (I). Revista de Derecho Privado(86), 773-840.

Angel Yagúez, R. D. (1993). Tratado de responsabilidad civil. Madrid: Civitas.

Betlem, G. (1993). Civil liability for Transfrontier Pollution. Graham \& Trotman/Martinus Nijhoff.

Boqueiro Rojas, E. (1997). Introducción al Derecho ecológico. México: Oxford.

Bourel, P. (1994). Un noveau cham d'exploration pour le droit international privé conventionnel: les dommages cuasés a l'environnement. En AA.VV., L'internationalisation du droit. Mélanges en l'honneur de Yvon Loussouarn (págs. 93-108). Paris: Dalloz. 
Cabanillas Sánchez, A. (2001). El daño ambiental y los derechos de las personas. En L. Martinez-Calcerrada y Gómez, Homenaje a Don Antonio Hernández Gil (Vol. 2, págs. 1149-1156). Madrid: Centro de Estudios Ramón Areces.

Corral Talciani, H. (1996). Daños ambientales y responsabilidad civil del empresario en la ley de bases del medio ambiente. Revista Chilena de derecho, 23(1), 143-177.

De La Barra Gili, F. (2002). Responsabilidad extracontractual por daño ambiental: el problema de la legitimación activa. Revista Chilena de Derecho, 367-415.

Egea Fernández, J. (2006). Relaciones de vecindad, desarrollo industrial y medio ambiente. En J. Esteve Pardo, Derecho del medio ambiente y administración local (págs. 389-426). Madrid: Civitas.

Esplugues Mota, C., \& Iglesias Buhigues, J. L. (2011). Derecho Internacional Privado (5a. ed.). Valencia: Tirant Lo Blanch.

Esteve Pardo, J. (2006). Derecho y medio ambiente: problemas generales: El Derecho del medio ambiente como Derecho de decisión y gestión de riesgos. Revista electrónica del Departamento de Derecho de la Universidad de La Rioja, REDUR, 7-16.

Fach Gómez, K. (2004). The law applicable to cross-border environmental damage: from the european national systems to Rome II. Yearbook of Private International Law, VI, 291-318.

Fernández De Gatta Sánchez, D. (2004). Derecho ambiental: aspectos generales sobre la protección jurídica del medio ambiente. E-Derecho Administrativo(12).

García Castrejón, J. (2006). Panorama de la responsabilidad internacional por daño ambiental. En M. d. Carmona Lara, \& L. Hernández Meza, Temas selectos de Derecho ambiental (págs. 467-508). México: Instituto de investigaciones jurídicas de la UNAM.

Gomis Catalá, L. (1998). Responsabilidad por daños al medioambiente. Pamplona: Aranzadi.

González Campos, J. D. (1991). Derecho Internacional Provado. Parte Especial. (4a ed.). Madrid: C. E. S. S. J. Ramón Carande. 
Jordano Fraga, J. (2000). Responsabilidad civil por daños al medio ambiente en Derecho Público: última jurisprudencia y algunas reflexiones de lege data y contra lege ferenda. Jordano Fraga, Jesús. «Responsabilidad civil por daños al medio ambiente en Derecho Público: última jurisprudencia y algunas reflexiRevista española de Derecho Administrativo(107), 351-371.

Juste Ruíz, J. (1996). Contaminación transfronteriza y reparación de daños ambientales: las lecciones de Chernobil. Revista de la Asociación de Derecho Ambiental Español(2), 77-94.

Kadner Graziano, T. (2007). The law applicable to cross-border damage to the environment. A commentary on article 7 of the Rome II Regulation. En A. Bonomi, \& P. Volken, Yearbook of Private International Law (Vol. IX, págs. 7186). Sellier/Staempfli.

Llamas Pombo, E. (2009). Requisitos de la acción colectiva de responsabilidad civil. Diario La Ley(7141).

Martín Mateo, R. (1998). Prospectiva de la tutela del medio ambiente en España. En A. VV., Primeras conferencias sobre el medio ambiente (págs. 1-9). Castellón: Comite Economic i Social de la Comunitat Valenciana.

Martín Mateo, R. (2000). Avances en la efectividad de la responsabilidad ambiental. En J. A. Moreno Martínez, Perfiles de la responsabilidad civil en el nuevo milenio (págs. 322-331). Madrid: Dykinson.

Martínez Vásquez De Castro, L. (1998). La protección civil del medio ambiente. Martínez Vásquez De Castro, Luis. Primeras conferencias sobre el medio ambiente, 1-15.

Molina Sandoval, C. A. (2005). Prevención del daño ambiental: perspectivas de una posible solución mediante la incorporación de los "punitive damages" en el derecho argentino. Revista de Derecho Privado(8), 191-209.

Palao Moreno, G. (1998). La responsabilidad civil por daños al medioambiente. Valencia: Tirant Lo Blanch.

Peña Chacón, M. (2006). Daño, responsabilidad y reparación ambiental. San José: IJSA.

Poveda Gómez, P., \& Vásquez Cobos, C. (2001). La reparación de los daños ambientales. Estudios comparativos entre el Anteproyecto de Ley de Responsabilidad Civil derivada de las actividades con incidencia ambiental y el Libro Blanco de la 
Comisión Europea sobre Reparación Medioambiental. Noticias de la Unión Europea(193), 59-72.

Roca Trías, E., \& Navarro Michel, M. (2011). Derecho de Daños (6a ed.). Valencia: Tirant lo Blanch.

Sebsay, D. A., \& Di Paola, M. E. (2003). El daño ambiental colectivo y la nueva Ley General del Ambiente. Anales de la Legislación Argentina(17).

Sidoli, O. C. (2004). Los daños punitivos y el derecho ambiental. elDial.

Siqueiros, J. L. (2002). La ley aplicable y la jurisdicción competente en casos de responsabilidad civil por contaminación transfronteriza. Anuario Mexicano de Derecho Internacional, II, 185-202.

Tamayo Jaramillo, J. (1986). De la responsabilidad civil (Vol. 1). Bogotá: Temis.

Vásquez García, A. (2004). La responsabilidad por daños al ambiente. Gaceta Ecológica(73), 45-62.

Vásquez Villar, A. (s.f.). Fiscalías Ambientales. En AA.VV., 2do Congreso Internacional de Medio Ambiente y Derecho Ambiental (págs. 45-62). Arequipa: LPG Editores.

"LA REVISTA INNOVARE NO SE HACE RESPONSABLE EN NINGÚN CASO DE LOS CONTENIDOS, DATOS, CONCLUSIONES U OPINIONES VERTIDAS EN LOS ARTÍCULOS PUBLICADOS, SIENDO ESTA RESPOSABILIDAD EXCLUSIVA DEL (DE LOS) AUTOR (AUTORES)" 